\title{
La identidad musulmana de los mudéjares de la Cuenca del Duero a finales de la Edad Media. Aportaciones desde la aljama de Burgos*
}

\author{
Muslim Identity of the Duero Basin Mudejars in the Late Middle \\ Ages. The Case of the Moorish Aljama of Burgos
}

\author{
Olatz VilLanueVa ZubizarReta ** \\ LUIS ARAUS BALLESTEROS ${ }^{\star \star *}$
}

\begin{abstract}
RESUMEN
La identidad musulmana de los mudéjares de la cuenca del Duero constituye un tema apenas abordado en la historiografía del mudejarismo castellano. En este trabajo se presentan algunas evidencias textuales, arqueológicas y patrimoniales que aportan datos sobre este Islam vivido en minoría, tanto en las aljamas más populosas y mejor estudiadas como en las de menor población y más desconocidas, como es el caso de Burgos.
\end{abstract}

\section{PALABRAS CLAVE}

Castilla, mudéjares, Islam, mezquitas, cementerios, ley de moros.

\begin{abstract}
Recent scholarship on Castilian Mudejars has rarely devoted itself to the Muslim identity of the Duero river-basin Mudejars. This study presents textual, archaeological and other cultural data regarding Islam as experienced by this minority both in the most populous and well-known Aljamas and in the smallest and lesser-known Muslim communities, such as that of Burgos.
\end{abstract}

\section{KEY WORDS}

Castile, Mudejars, Islam, Mosques, Cemeteries, Muslim law.

En los últimos años el estudio de los mudéjares de la Cuenca del Duero ha dado visibilidad histórica a una población que tradicionalmente había quedado en un segundo plano en la historiografía del mudejarismo castellano. Pese a los avances conseguidos, los mudéjares del norte siguen siendo los grandes desconoci-

\footnotetext{
* Fecha de recepción del artículo: 2013-10-17. Fecha de aceptación del artículo: 2014-02-11.

* Departamento de Historia Antigua y Medieval. Universidad de Valladolid. C.e.: olatz.villanueva@uva.es.

*** Investigador en Formación Contratado de la Universidad de Valladolid. C.e.: luis.araus.b@gmail.com.
} 
dos del panorama peninsular, acaso porque se trata de una población inmigrada de los territorios andalusíes a la que se le presupone una progresiva y temprana pérdida de identidad musulmana.

Hoy podemos decir sin embargo que en la cuenca del Duero existió a lo largo de toda la Edad Media un Islam vivido en minoría, del que conservamos una nutrida muestra de manifestaciones materiales e inmateriales en diferentes planos históricos de la sociedad castellana. Muchas de ellas, lo veremos a lo largo de estas páginas, constituyen evidencias palmarias del mantenimiento de la identidad musulmana por parte de los integrantes de las aljamas durienses hasta el final de la Edad Media, hasta la fecha misma del bautismo obligatorio de los musulmanes de Castilla dictado en $1502^{1}$. Se trata de datos que confirman el mantenimiento de la lengua, escritura y onomástica árabes por parte de estos mudéjares, de la organización de la población en aljamas, del conocimiento y regulación de la vida cotidiana según el derecho islámico o de la profesión de su fe islámica en vida (mezquitas) y tras su muerte (cementerios), en un grado más o menos similar al de otras comunidades peninsulares ${ }^{2}$.

Si hasta la fecha estas evidencias procedían en su mayoría de las aljamas más importantes de la Cuenca del Duero (Ávila, Valladolid, Arévalo o Cuéllar) y, por lo tanto, solo atestiguaban esta realidad en las más populosas e influyentes, nuevos datos (en esta ocasión, pleitos elevados a la Chancillería de Valladolid) permiten hoy corroborar esta condición a comunidades menores, como la de Burgos, una de las más septentrionales de la Península, donde residían en torno a un par de cientos de mudéjares.

\section{MOROS E MORAS DE LAS ALJAMAS DE LA CUENCA DEL DUERO}

Las comunidades mudéjares que se establecieron en las ciudades de la cuenca del Duero a lo largo de la Edad Media procedían del centro y sur peninsular, de los territorios islamizados que gradualmente fueron incorporados a la Corona de Castilla. Esto las hace diferentes de sus homólogas aragonesas e, incluso, de las castellanas del mediodía peninsular, formadas en su mayoría por población andalusí residual ${ }^{3}$.

1 El texto de esta orden y de otras que se dictan encaminadas, en palabras de la autora, hacia la primera expulsión, la de la fe (1492-1526), puede consultarse en CARRASCO MANCHADO, Ana Isabel, De la convivencia a la exclusión. Imágenes legislativas de mudéjares y moriscos. Siglos XIII-XVII, Ed. Sílex, Serie Historia Medieval, Madrid, 2012, pp. 233-237.

2 Vaya por adelantado nuestro sincero agradecimiento a Guillem Rosselló Bordoy y a Javier Jiménez Gadea por su inestimable ayuda en la lectura y traducción de ciertos textos en árabe y a Luis Vasallo Toranzo por facilitarnos algunos documentos del Archivo de la Real Chancillería de Valladolid, sin cuya información este trabajo no hubiera sido posible.

${ }^{3}$ La cuestión de los orígenes del mudejarismo de las tierras del Duero es un asunto no del todo resuelto, pero sobre ello pueden consultarse obras como: MAÍLLO SALGADO, Felipe, «Sobre la presencia de los muslimes en Castilla la Vieja en las Edades Medias", Actas del III Curso de Cultura Material: Repoblación 
Los tributos que mudéjares y judíos tuvieron que pagar a la hacienda regia en concepto de impuestos especiales por permitírseles vivir en estas tierras y practicar sus religiones, nos dan a conocer la identidad y presencia de las comunidades que pagaron tales tributos en tierras castellanas ${ }^{4}$. De ello se desprende que este mudejarismo fue un fenómeno eminentemente urbano, pues es en las villas de la cuenca donde encontramos avecindados a los mudéjares. Y su importancia no debía de ser baladí ya que las cantidades de las pechas anotadas revelan que algunas de las aljamas del Duero (por ejemplo, Ávila, Ágreda, Arévalo o Valladolid) pagaban más que cualquiera de las del Arzobispado de Toledo y el Obispado de Cuenca, de los Obispados de Coria, Plasencia y Badajoz (a excepción de Hornachos), del Arzobispado de Sevilla y los Obispados de Cádiz, Córdoba y Jaén o del de Cartagena (sólo los del Valle de Ricote contribuían más que los de Ágreda, Arévalo o Valladolid $)^{5}$.

Atendiendo a los datos anotados en esos registros fiscales, se desprende que existían en torno a una veintena de aljamas moras reconocidas en el valle del Duero y, en función de las cantidades pechadas, su población podría cifrarse a finales de la Edad Media, aún con el riesgo que ello conlleva, en más de 5.000 mudéjares ${ }^{6}$, que podrían incluso aproximarse a los 10.000 si atendemos a los cálculos del profesor Ladero?.

Entre ellas existe un notable desequilibrio poblacional. La más populosa era la comunidad de la ciudad de Ávila con un millar de mudéjares, sin duda, referente para el resto de las aljamas del norte y centro peninsular, y hoy para los historia-

y Reconquista (Aguilar de Campoo, 1991), Madrid, 1993, pp. 17-22. ECHEVARRÍA ARSUAGA, Ana, «La "mayoría" mudéjar en León y Castilla: legislación real y distribución de la población (siglos XI-XIII)", En la España Medieval, 26, 2006, pp. 7-30. VILLANUEVA ZUBIZARRETA, Olatz, «Los escenarios de la sociabilidad para los mudéjares de la cuenca del Duero: la vida en las morerías y el duelo en las maqbaras». J. C. Martín Cea (Coord.) Convivir en la Edad Media, Ed. Dossoles, Burgos, 2009, pp. 347-372.

${ }^{4}$ Conocemos la pecha o cabeza de pecho, una cantidad que cada morería y judería debía de pagar desde época de Enrique III en reconocimiento a la protección que recibían del señorío real. El servicio y medio servicio fue un pago que empezó en 1388 siendo extraordinario y acabó por ser anual durante el reinado de los Reyes Católicos, del que sólo conocemos los datos de los años 1463, 1464 y 1501. A esto hay que sumar el castellano de oro anual, que ascendió a dos en los años 1495 y 1496, aplicado a los propietarios de hacienda propia, y que tuvo que ver con la presión fiscal resultante de la conquista de Granada.

${ }^{5}$ La información detallada puede consultarse en diversos trabajos de LADERO QUESADA, Miguel Ángel, Los mudéjares de Castilla en tiempo de Isabel I. Valladolid, 1969; «Datos demográficos sobre los musulmanes de Granada y Castilla en el siglo XV", Anuario de Estudios Medievales, 8, 1972-1973, pp. 481-490; «Los mudéjares de Castilla en la Baja Edad Media», Actas del I Simposio Internacional de Mudejarismo (Teruel, 1975), Madrid-Teruel, 1981, pp. 345-390.

${ }^{6}$ Con esta misma información fiscal, Montes calcula que los de Castilla la Vieja representaban entre un 20 y un $25 \%$ del total de los mudéjares castellanos que, en su opinión, vivían en «muchas y bien pobladas» aljamas. MONTES ROMERO-CAMACHO, Isabel, "Las comunidades mudéjares de la Corona de Castilla durante el siglo XV», Actas del VIII Simposio Internacional de Mudejarismo. De mudéjares a moriscos: una conversión forzosa, vol. I, Teruel, 2002, p. 372.

7 Ladero ha calculado para fines del siglo XV que la Corona de Castilla contaba con unos 20.000 a 25.000 mudéjares, de los cuales entre el 35 y el $40 \%$ vivían al norte del Sistema Central, entre el 20 y el $30 \%$ en Castilla la Nueva y Extremadura, el $10 \%$ en Andalucía y en torno a un $20 \%$ en Murcia: LADERO QUESADA, Miguel Ángel, "Los mudéjares en la Edad Media Española», Las tres Culturas, Real Academia de la Historia, Madrid, 2004, pp. 37-122. 
dores que estudiamos el mudejarismo castellano por la excepcional riqueza de sus vestigios ${ }^{8}$. Le seguían en población Valladolid ${ }^{9}$, Arévalo y Ágreda ${ }^{10}$ con más de medio millar de mudéjares, Segovia ${ }^{11}$ y Burgos $^{12}$ con más de doscientas y a continuación las morerías de Deza, Aranda de Duero ${ }^{13}$, Medinaceli, El Barco de Ávila, Piedrahita, Palencia y Ayllón, con más de un centenar de mudéjares habitando en ellas. En Medina del Campo, Cuéllar, Sepúlveda, San Esteban de Gormaz y Peñaranda de Duero apenas llegarían a los cien. Y, finalmente, localidades como Carrión de los Condes, Sahagún y Peñafiel, cuyas poblaciones moras (no constituidas en aljamas) tributaban entre 400 y 200 maravedíes, frente a los 8.000 ó 6.000 de Ávila y Valladolid, lo cual da una idea de su presencia y peso específico mudéjar en cada uno de esos lugares.

\section{EL ISLAM MUDÉJAR DE LAS TIERRAS DEL DUERO}

La expresión del Islam de la Cuenca del Duero es mudéjar porque, como ya se ha dicho, sólo los territorios de las actuales provincias de Soria y Segovia formaron parte de la antigua demarcación andalusí de la Marca Media. Pero pese a lo que pudiera pensarse, las manifestaciones del Islam mudéjar de las tierras del Duero no son en absoluto desdeñables y demuestran el mantenimiento de la identidad musulmana entre los integrantes de estas comunidades hasta el momento de su bautismo obligatorio en 1502.

8 Seguramente por ello fue una de las primeras en contar con estudios específicos (fundamentalmente, a cargo de S. de Tapia) y con un Proyecto de Investigación propio «Mudéjares y moriscos en Castilla: el caso de Ávila» (VA045A09) llevado a cabo por el mencionado Grupo de Investigación Mudéjares y Moriscos. Por citar algunas de las obras más importantes, además de otros estudios específicos que se referirán más adelante: TAPIA SÁNCHEZ, Serafín de, La comunidad morisca de Ávila, Universidad de Salamanca, Salamanca, 1991; ECHEVARRÍA ARSUAGA, Ana, The City of the Three Mosques: Ávila and its Muslims in the Middle Ages. Serie «Textualia: Jewish, Christians and Muslims in their Texts». Wiesbaden, Reichert Verlag, 2011; JIMÉNEZ GADEA, Javier; ECHEVARRÍA ARSUAGA, Ana; TAPIA SÁNCHEZ, Serafín de, y VILLANUEVA ZUBIZARRETA, Olatz, La memoria de Alá. Mudéjares y moriscos de Ávila, Catálogo de la Exposición, Ediciones Castilla, Valladolid. 2011.

${ }^{9}$ Para una visión general: VILLANUEVA ZUBIZARRETA, Olatz, «Vivir y convivir bajo la señal de la media luna: mudéjares y moriscos en Valladolid». En El arte mudéjar en Valladolid. Diputación de Valladolid, Valladolid, 2007, pp. 19-33.

10 Desde el punto de vista urbanístico y patrimonial: RETUERCE, Manuel, y HERVÁS, Miguel Ángel, «Apuntes sobre la antigua morería de Ágreda (Soria)». De la Edad Media al siglo XVI. Jornadas Históricas del Alto Guadalquivir, 2000, pp. 41-61. HERVÁS, Miguel Ángel, y RETUERCE, Manuel, «Hallazgos arqueológicos en la morería de Ágreda». Actas del V Congreso de Arqueología Medieval Española, Vol. II, Valladolid, 2001, pp. 897-912.

${ }_{11}$ Marqués de LOZOYA, La morería de Segovia, Colección Monográfica Africana n.․, Instituto de

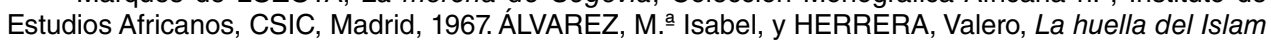
en la ciudad de Segovia, Ayuntamiento de Segovia y Junta de Castilla y León, Segovia, 2007.

12 Unos primeros apuntes en: LÓPEZ MATA, Teófilo, «Morería y judería», Boletín de la Real Academia de la Historia n. 129, 1951, pp. 335-384; TORRES BALBÁS, Leopoldo, Algunos aspectos del mudejarismo urbano medieval, Real Academia de la Historia, 1954, pp. 25-34. Más recientemente: CADIÑANOS BARDECI, Inocencio, Judíos y mudéjares en la provincia de Burgos, Excma. Diputación de la Provincia de Burgos, Burgos, 2011, pp. 115-132.

13 CADIÑANOS BARDECI, Inocencio, Judíos y mudéjares..., pp. 143-150. 
Las evidencias que sustentan esta aseveración son múltiples y de variada naturaleza, pero vistas en conjunto permiten advertir el bagaje islámico de estos mudéjares.

En contraposición a algunos testimonios de la época que lamentan la pérdida de uso de la lengua árabe por parte de los mudéjares castellanos ${ }^{14}$, nos han llegado otros que denotan sin embargo su empleo. Resulta muy difícil saber si los mudéjares del Duero hablaban el árabe de forma habitual (se sostiene que no), pero a tenor de las referencias escritas que hacen alusión al uso de la lengua o al empleo propiamente de la escritura arábiga en diferentes manifestaciones y soportes, cabría pensar que existía un conocimiento (¿más o menos extendido?) de esta lengua. Veamos algunos ejemplos.

En 1493 Sancho Pérez Machuca y los hermanos Abdalla y Mahomad Alfaquí, hijos de Alí, vecinos de Arévalo, litigaron en la Chancillería de Valladolid por los reparos hechos en una casa y huerta propiedad del primero y alquilada a la familia Alfaquí ${ }^{15}$. Como prueba, se traduce una escritura encuadernada en pergamino escrita en letra arábiga, correspondiente al «almahar ${ }^{16}$ que Ali Alfaquí avía fecho a Axa su muger, y se mandó a Mahomad Alfaquí, moro, alfaquí desta villa que presente estava que lo traslade de arávigo en romançe o en letra castellana por que pueda ser visto e esaminado claramente lo en él contenido". Resulta interesante la advertencia de que además de su traducción a la lengua castellana, se transcriba igualmente en grafía latina, lo que podría estar indicándonos el uso de la escritura árabe (aljamiado) por parte de estos mudéjares ${ }^{17}$, como en el ejemplo conocido de la partición de la herencia de Ibrahīm Abū l-Layd de Medinacelli de los años 1459-60 ${ }^{18}$.

Otra muestra curiosa de empleo de la escritura arábiga en un documento notarial es la basmala que encabeza el testamento de Ramiro Alcalde, redactado y escrito en castellano en 1497 e inserto en un pleito de 1501 elevado a la Chanci-

${ }^{14}$ El alfaquí segoviano Içe de Gebir, en su Breviario sunní de 1462, advertía que «los moros de Castilla (...) han perdido las escuelas del arábigo» y el muftí magrebí al-Wansarisi, ya en 1495, que los de Ávila «perdieron la lengua totalmente». Respectivamente citados en: EPALZA, Mikel de, «La voz oficial de los musulmanes hispanos, mudéjares y moriscos, a sus autoridades cristianas: cuatro textos, en árabe, en castellano y en catalá-valenciano", Sharq al-Andalus, 12, 1995, pp. 284-285, y MAÍLLO SALGADO, Felipe, «Consideraciones acerca de una fatwa de Al-Wansarisi», Estudia Histórica, Historia Medieval, III-2, 1985, pp. 181-192.

15 ARChVa, PI. Civiles, Alonso Rodríguez (D), C. 14-4.

${ }^{16}$ Almahar: adaptación del árabe mahr, plural muhûr. Hay una forma en femenino muhûra. De la raíz $\sqrt{ }$ MHR, con diferentes significados entre los que se halla el verbo MAHARA = dotar una mujer, darle

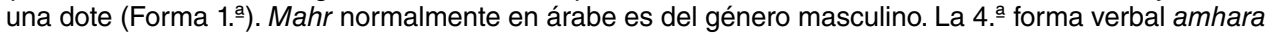
significa casarse con una mujer que ha recibido dote. BELOT, J. B., Vocabulaire Arabe-Français, Beyrouth, 1898, 5. ${ }^{\text {a }}$ ed.

17 A continuación, se inserta la traducción de la carta que comienza así: En el nombre de Allah el piadoso apiadador ayudador e allali e abrimiento e albriçiamiento a los creyentes e la salvaçión de... nuestro cabdillo e nuestor governador Mahomad el hnrrado e sobre llos suyos e sus mugeres e sus hijos savlaçión salva mucha syguiente los lloros son a... al qual que no son blançan las suerte de las ymaginaçiones en las maravillos y sy más de sus obras de terminaçión e notoria los juyçios...

18 VIGUERA, M. ${ }^{\text {a }}$ Jesús, «Partición de herencia entre una familia mudéjar de Medinaceli», Al-Qantara, vol. III, fasc. 1 y 2, 1982 , pp. 73-133. 
llería de Valladolid por Mahoma y Farax Alcalde, hermano e hijo respectivamente del finado ${ }^{19}$. El documento de dos folios de extensión inserta en la parte superior, donde en otros testamentos suele ir la cruz, la basmala (En el nombre de Dios, el Clemente, el Misericordioso), fórmula recitativa con la que se abre el Corán y todas sus suras y, por extensión, la mayoría de los textos árabes, religiosos o no. Está escrita en letra cursiva, con soltura, en tinta y trazo diferentes al resto del documento, por otra mano que la que redactó el escrito y a posteriori. Parece letra de alguien que está acostumbrado a escribir en árabe, al que no le supone ninguna dificultad la escritura de derecha a izquierda. Ello, y el hecho de que la fórmula sea tan común y conocida, hace que se tome ciertas licencias ortográficas ${ }^{20}$, que no parecen indicativas del desconocimiento de la lengua árabe, por las razones ya expresadas, sino, por el contrario, una relajación en su escritura, con un cierto desinterés en reflejar correctamente ésta en toda su plenitud ortográfica. En definitiva, el carácter marcadamente islámico de la basmala nos indica el interés por islamizar el contenido del documento, por enmarcar éste en un contexto jurídico islámico o por afirmar la pertenencia al Islam de su titular.

También la rúbrica en árabe en ciertos documentos oficiales muestra el empleo de la grafía y la lengua árabes entre los mudéjares del Duero. Es el caso de Çulema de $\mathrm{Ayu}^{21}$, un guadamacilero de la localidad soriana de Ágreda, que en un pleito que sostuvo en 1492 con un vecino de Guadalajara por una obligación incumplida, refleja su firma y nombre en árabe: Sul-Liman de Ayūb ${ }^{22}$. O la excepcional y curiosa rúbrica de Ibrahim al-Lajmī Xarafi que actuando como alfaquíi ${ }^{23}$ en un pleito elevado en 1501 a la Chancillería de Valladolid por parte de dos miembros

19 ARChVa, PI. Civiles, Zarandona y Walls (O), C. 1168-1.

20 . En opinión de Javier Jiménez Gadea, la frase carece por completo de puntos diacríticos. Deberían estar en las letras ba, nun y ya (ésta en el alargamiento vocálico de la penúltima sílaba de la última palabra, الرحيم). No se marcan las mociones vocálicas, la šadda de الله ni el alargamiento vocálico en الرحمن. Se simplifica la letra sin, marcando un solo alveolo. Se duplica el alif inicial de الرحن y الرنه.

De todas estas anomalías ortográficas, las tres primeras deben considerarse consecuencia de una escritura cursiva y rápida, que conoce la frase que está escribiendo y que pretende economizar medios. Las anomalías señaladas son las propias, por ejemplo, de la epigrafía monumental o lapidaria, que suele trabajar sobre soportes duros y con otros estilos de escritura (cúfico, fundamentalmente), donde resulta más complejo y laborioso marcar todos los signos gráficos que ayudan a la lectura de las palabras. En realidad, y paradójicamente, estas ausencias denotan un buen conocimiento del árabe (en este caso, al menos, de la basmala). La última anomalía reseñada, sin embargo, parece más extraña. La repetición del alif inicial del artículo más bien parece un despiste, que el autor corrige inmediatamente en la última palabra. Demuestra con ello, pues, que sabe cómo se escribe.

${ }^{21}$ Que también es mencionado a lo largo del proceso del pleito como Zuleman y de apellido Allu o Dallu.

22 ARChVa, PI. Civiles, Pérez Alonso (F), C. 678-1.

${ }^{23}$ En 1484, Abrahen Xarafí aparece como «alfaquí del aljama de los moros de la villa de Valladolid». MOLÉNAT, Jean Pierre, «Alcaldes et alcaldes mayores de moros de Castille au XV' siècle, en Regards sur al-Andalus (VIIle-XVe siècle), Casa de Velázquez, Madrid, 2006, p. 153. Pero también sabemos de su nombramiento como alcalde mayor de las aljamas de Castilla a finales de siglo. MOLÉNAT, Jean Pierre, «À propos d’Abrahen Xarafí: les alcaldes mayores de los moros de Castille au temps des Rois Catholiques", en VII Simposio Internacional de Mudejarismo (Teruel, 19-21 de septiembre de 1996). Teruel: Centro de Estudios Mudéjares, 1999, p. 175-184. 
de la familia Alcalde de esa ciudad, firma en dos renglones, plasmando en el superior en grafía árabe Ibrahim al-Lajmī y en el inferior en latina Xarafi ${ }^{24}$.

Por su parte, los ejemplos epigráficos descubiertos en varias inscripciones funerarias de la ciudad de Ávila enriquecen este panorama. El epitafio de la tumba de Abd Allah ibn Yūsuf al-Ganiyy, muerto en 1492, desvela en letra cursiva entre una serie de jaculatorias religiosas, la identidad del difunto y las trágicas circunstancias de su muerte: «[En el nombre de Dios, el Clemente, el Misericordioso. Éste es el sepulcro de Abd] Allăh ibn Yûsuf el Rico, asesinado injustamente, ique Dios se apiade de él!. Murió [en el día...del mes...][...] su imperio, del año de la Hégira de nuestro profeta Muhammad, ique Dios lo bendiga y lo proteja!, [ocho] cientos [noventa y siete]. ¡Que Dios nos reúna con Él en el Paraíso! No hay poder ni gloria excepto en Dios, el Altísimo, el Sabio. No hay vencedor excepto Dios " ${ }^{25}$. En otros casos, la leyenda recurre a simples jaculatorias o versículos coránicos, como el cipo del siglo XV que en siete renglones evoca el versículo XXVIII, 88, que dice «iNo invoques a otro dios junto con Dios! ¡No hay más dios que Él! ¡Todo perece, salvo Él! ¡Suya es la decisión! ¡Y a Él seréis devueltos!» ${ }^{26}$ o la estela de los siglos XIII-XIV que, aunque muy erosionada, conserva al final del renglón la palabra Dios o para Dios ${ }^{27}$.

Otro elemento que evidencia la identidad islámica de estos mudéjares es el mantenimiento de ciertos rasgos de la estructura onomástica musulmana. La legislación castellana acordó, desde las Cortes de Palencia de 1313 en adelante, la prohibición de que los mudéjares usaran nombres cristianos y, como hemos visto en ejemplos anteriores, algunos miembros de estas comunidades expresaban sus patronímicos según la estructura musulmana compuesta por el ism, kunya, nasab, nisba y laqab: Ibrahīm Abū I-Layd, Brayme al-Lajmī Xarafi o Abd Allah ibn Yūsuf al-Ganiyy. Pero en su mayoría, construyeron su apelativo con el ism arábigo y la forma castellanizada del nasab. Algunas relaciones nominales, como la de los integrantes de la aljama de Valladolid reunidos en 1414, dejan entrever sin embargo otras formas derivadas de la estructura onomástica árabe: convienen a saber Hamet Alfaquí, Braen Ronda, Maestre Aly Ojos de Enamorado, Mahomat Pynacho, Ramiro hermano del Allcalde, Mahomat Gordo, Muça Conde, Hebraen hijo de doña Odylen, Hebrahen Conde, Aly Guidado, Adolea nieto de Ostyn, Brahen Xedel, Aly hermano de Buenaño, Mahomat hijo de Brahen el viejo, Aly Sancho, Aloçenen hijo de Maestre By, Ali Morahen, Maestre Hamet de Madrit, Ramiro so-

\footnotetext{
${ }^{24}$ ARChVa, PI. Civiles, Zarandona y Walls (O), C. 1168-1. Agradecemos a los profesores del Área de Ciencias y Técnicas Historiográficas de la Universidad de Valladolid, José Manuel Ruiz Asencio e Irene Ruiz Albi, su inestimable ayuda en la transcripción de esta firma.

25 JIMÉNEZ GADEA, Javier, «Acerca de cuatro inscripciones árabes abulenses», Cuadernos Abulenses, n.ำ 31, 2002, pp. 25-71. (Museo de Ávila, n.ำ inv. 89/20/4/ 2 y 3).

${ }^{26}$ El texto de la inscripción dice: «la muerte convierte el paso - del tiempo, de la vida- en un oratorio y [la muerte] extingue el paso en Él. Todo perece salvo su Faz. Suya es la decisión y a Él seréis devueltos». JIMÉNEZ GADEA, Javier, «Estelas funerarias islámicas de Ávila: clasificación e inscripciones», Espacio, Tiempo y Forma, Serie I, Nueva época, Prehistoria y Arqueología, Tomo 2, 2009, pp. 221-267, 262-263. (Museo de Ávila, n.․inv. 03/64/B32).

27 Ibidem, pp. 221-267, 230, fig. 16 (Museo de Ávila, n.ํinv. 00/29/MF71).
} 
brino del Alcalde, Aodalla Conde, don Aly Allcalde, Maestre Mahoma talcafeus, Haray hijo del viejo e otros moros asaz de la dicha morería e aljama ${ }^{28}$. Vemos pues entre ellos a algunos mudéjares que adoptan la forma del ism y el nasab castellanizado que expresan el parentesco mediante la alusión a hijo, hermano o nieto (Ramiro hermano del Allcalde, Hebraen hijo de doña Odylen, Adolea nieto de Ostyn, Aly hermano de Buenaño, Mahomat hijo de Brahen el viejo, Aloçenen hijo de Maestre By, Ramiro sobrino del Alcalde), pero también podríamos ver la forma del ism junto al laqab en nombres como Hamet Alfaquí, Aly Ojos de Enamorado y Mahomat Gordo, o el ism junto al nisba en Hamet de Madrit.

En otro orden de cosas, la regulación de la vida cotidiana según el derecho islámico cuenta con cada vez más evidencias documentales que invitan a pensar que los mudéjares del Duero se regían por textos legales como las Leyes de Moros redactadas en castellano y en Castilla en el siglo XIV o el Memorial y sumario de los principales mandamientos y develamientos de nuestra santa Ley y Çunna escrito en 1462 por el alfaquí segoviano Içe de Gebir ${ }^{29}$. Vimos anteriormente el ejemplo del acuerdo matrimonial o almahar de los vecinos de Arévalo Ali Alfaquí y su mujer $\mathrm{Axa}^{30}$, y son cada vez más numerosos los hallazgos de testamentos $y$ repartos de bienes familiares que se rigen según la ley e açunna de moros. A los ya conocidos de Medinaceli, la familia Alcalde de Valladolid ${ }^{31}$ o los Santo Tomé de Ávila ${ }^{32}$, nuevos documentos inéditos arrojan más luz sobre el tema.

Es el caso del reparto de la herencia de maestre Alí, herrador vecino de Cuéllar, que tras la conversión trocó su nombre por el de Francisco Hernández de Palacios, sobre la cual los herederos litigaron en la Real Chancillería de Valladolid hasta obtener sentencia en grado de revista en 1519. Esta sentencia reconocía la validez para estos moriscos de su «ley e costumbre muy antigua vsada e guardada en tiempo de moros", por la que «todo lo que resçebían las hijas de los tales moros con su casamiento, como de padres lo resçebían al tiempo de los tales casamientos lo fazçyan suyo, propio e de su propio patrimonio sy ser obligadas las tales hijas a traer a colaçión ni partiçión los tales vienes dotales avnque quisiesen venir a heredar en los bienes e herençia de los dichos sus padre e madre ya defuntos. Lo otro porque la tal ley e costumbre se avía usado e guardado no

\footnotetext{
${ }^{28}$ MORATINOS GARCÍA, Manuel, y VILLANUEVA ZUBIZARRETA, Olatz, "Consecuencias del decreto de conversión al cristianismo de 1502 en la aljama mora de Valladolid», en Sharq al-Andalus, Revista de Estudios Mudéjares y Moriscos, vol. 16-17 (1999-2002), Homenaje Leonard P. Harvey, 2004 pp. 119.

${ }_{29}$ CARMONA GONZÁLEZ, Alfonso, «Textos jurídico-religiosos islámicos de las épocas mudéjar y morisca», Areas: Revista Internacional de Ciencias Sociales, n.․ 14, 1992, pp. 13-26.

${ }^{30}$ Las Leyes de Moros (versión Gayangos) dedican el Título CCCVIII a De como han de fazer los almahares.

${ }^{31}$ VILLANUEVA ZUBIZARRETA, Olatz, «La alcallería mudéjar en Valladolid con nombres propios. La familia Alcalde». en Castilla y el mundo feudal. Homenaje al profesor Julio Valdeón Baruque, Junta de Castilla y León y Universidad de Valladolid, Tomo II, Valladolid, 2009, pp. 69-86.

32 PASCUAL CABRERO, José Luis, «Pleito por la herencia de Abdallá de Santo Tomé, según «La Ley e Açunna de Moros»»", Espacio, Tiempo y Forma, Serie III, Historia Medieval, Tomo 26, 2013, pp. 275-302.
} 
solamente en tiempo de moros, pero aún después que las tales fijas dotadas veniesen a heredar al tiempo que fuesen christianas e convertidas a nuestra santa fee católica, aunque al tiempo que los tales padre e madre de las dichas sus hijas dotadas mandasen syendo christianos lo contrario en sus testamentos, e asý se avía vsado e guadado la dicha costumbre de tiempo ynmemorial a aquella parte en todas e qualesquier personas que el dicho tyempo oviesen syendo moros e después de christianos e en tiempo de christianos donde se hobiesen de traer a colaçión las dichas dottes» ${ }^{33}$, reconociendo así como legítimas las dotes entregadas a sus hijas en el momento de casarse conforme a la «ley e azuna» ${ }^{34}$. Y no debió de ser éste un caso excepcional, ya que la sentencia concluye que este proceder «hera muy público e notorio en la dicha villa de Valladolid e en las otras çibdades e villas e lugares destos nuestros reynos donde avían acaeçido las semejantes cabsas e pleitos» 35 .

Y es más, no solo parece que estuviera vigente en las aljamas más importantes y populosas de la cuenca del Duero, como dice el documento, sino también se adoptaba en otras menores, como fue el caso de la de Burgos, que más tarde veremos.

Resulta igualmente interesante en lo tocante a esta cuestión jurídica, los numerosos y variados testimonios de juramento que los mudéjares castellanos hacen conforme a su ley y religión, en distintas situaciones y circunstancias. Ya en las Cortes de Jerez de 1268 se fijó la forma en la que éstos debían hacerse: «los moros han su jura apartada mente que deben faser enesta guisa: deuen yr tanbien el que ha de jurar como el que deue faser la jura ala puerta dela mesquita sy la oviere, sy non en el logardol mandare el jurador; e el moro que oviere de jurar deue estar de pie e tornarse de cara e alçar las manos contra el medio dia al que llaman ellos alquibla, et aquel que deue de tomar la jura deue de desir estas palabras: juras que tu fulano moro por aquel Dios que non ha otro synon el, aquel que es demandador e començador e destroydor e alcançador de todas las cosas, e crió aquesta parte de quibla contra que tu fases oraçion, et otrosy jurasme por lo que rresçibio Jacob dela fe de Dios para sy e para sus fijos, e por el omenaje que fiso dela guardar, e por la verdat que tu tienes que puso Dios en la boca de Mahomad fijo de Abdalla quando lo fiso su profeta e mandadero, según que tu cree, que esto que yo digo non es verdat, o que es asy como tu dises; et sy mentiras juras que seas apartados de todos sus bienes de Dios et de Mahommad aquel que tu dises que fue su profeta e su mandadero, e que non ayas y parte con el nin con

${ }^{33}$ ARChVa, Registro de Ejecutorias, C. 338, 69, fol. 16v. A propósito del tiempo de moros, resultan muy sugerentes las menciones en la tasación de bienes que se inserta a una camisa morisca del tiempo viejo, tres tocas moriscas de listas del tiempo viejo (fol. 7b-6r) o un manttillo açul del tiempo viejo enforrado muy rotto (fol. 88-6v), que entendemos que estarían haciendo alusión a la vestimenta específica que los mudéjares se vieron obligados a portar tras sucesivos decretos dictados en pro de la diferenciación física. VILLANUEVA ZUBIZARRETA, Olatz «Regulación de la convivencia con los mudéjares en las ciudades de la cuenca del Duero", La convivencia en las ciudades medievales, Logroño, 2008, pp. 341-357.

34 Ibidem, fol. 15v.

35 Ibidem, fol. 16v. 
los otros profetas en ninguno de los paraysos, mas todas las penas que dise en el al coran que dara Dios a los que non creen enla tu ley vengan sobre ty; et a todo esto sobre dicho, deue responder el moro que jura, ASY LO JURO, et disiendo todas estas palabras el mismo asy como las dixiere aquel que toma la jura desde el comienço fasta el cabo, et sobre todo esto desir AMEN» ${ }^{36}$.

Así, cuando en 1499 el segoviano Alibraro Durame participa como alarife juez árbitro en la partición del Palacio Real de San Martín de su ciudad, se le toma juramento, al igual que los otros «partidores» cristianos, y lo hace «a Ala que tiene por su criador... e a las palabras de su alcoran que dixo fueron dichas por su profeta Mahoma " ${ }^{37}$. En Valladolid, por las mismas fechas (1491) y en circunstancias similares, el maestre carpintero Amete Carretón fue requerido para testificar en un pleito por ciertas desavenencias en las obras llevadas a cabo en unas casas de la Corredera de San Pablo. Y prestó el compromiso jurando por el nombre de Viley labiçuanan buelta la cara azía las parte de oryente tocada su mano con la mía a el qual es alcançador vengador vençedor destroydor de todas las cosas del mundo aquel que está puesto azia las partes de alquibia donde los moros continúan a fazer su oraçión e por las palavras y fueron puestas en la boca de su profeta Mahoma donde se derige e declara su alcorán e como sy este juramiento le fuese tomado por su propio alfaqui, abierto el alcorán. puesta su mano derecha sobre él, como buen moro, teniendo a Alá e a sus mandamiento, dixese la verdad de lo que le fuese preguntado e supiese sobre esto que hera presentado por testygo e que si la verda jurase dixese e declarase que la todo poderoso por ynterçesyón de su profeta mahoma apiadase a el e a sus cosas casa e fijos e generaçión e sy el contraryo de la verdad jurase, veniese sobre él e sobre ellos todas las plagas e maldiçiones que están escriptas en su ley ${ }^{38}$.

En otras ocasiones, la fórmula jurídico-religiosa se inserta en la redacción testamentaria, como en el caso del alcaller vallisoletano Ramiro Alcalde que el 15 de octubre de 1497, estando dolyente en su cama de çierta dolençia que Dios le quiso dar, estando firme en su juyçio e entendimiento, dijo que, acordándose de la muerte, aquella que es natural a todas las criaturas formadas, que se afirmava y se afyrmó que no ay más de un solo Dios cryador que fiso a todas las cosas en que el firmemente crehe e adora, e crehe que Mohamad fue su siervo y su mensajero, e que todo lo que dijo de su parte es verdad, y que es verdad que ay parayso para los buenos y justos y que ay ynfierno para los malos, e que las gentes an de ser resuçitadas para el día del juycio a dar cuenta de sus obras, e que en esta crehençia a vevido e vivirá lo que a Dios pluguiere, e que en ella morirá quando aya de morir, e que en aquella crehençia será rresuçitado el día del juy-

${ }^{36}$ Cortes de los antiguos Reinos de León y Castilla, I. Ed. Real Academia de la Historia, Madrid, 1861, p. 84.

37 ÁLVAREZ, M. a Isabel, y HERRERA, Valero, La huella del Islam en la ciudad de Segovia, Ayuntamiento de Segovia y Junta de Castilla y León, Segovia, 2007, s.p.

38 ARChVa, PI. Civiles, Moreno (F), C. 1400-6. 
$\operatorname{sio}^{39}$. Además, y como ya avanzamos, refrendó su fe con el encabezamiento de la baslama en la parte superior del testamento.

Precisamente, la profesión de la fe islámica por parte de estos mudéjares castellanos cuenta con numerosos y variados testimonios. Uno de los más explícitos sin duda es la existencia de mezquitas o almajís, como lugares de reunión y oración de la comunidad. Disponemos de la descripción de la de Valladolid, inserta en un pleito que mantuvieron la aljama y el cabildo de la Colegiata como consecuencia del decreto de bautismo obligatorio de 1502 por el cual la institución eclesiástica entendía que ponía fin al arrendamiento del barrio como morería y al mantenimiento en pie de edificios relacionados con su anterior fe, como era el caso de este almaji ${ }^{40}$. Esa descripción nos descubre una construcción muy buena e muy bien labrada e pintada ricamente, compuesta por una casa grande que llamaban almají donde (...) hacían oración los dichos moros del dicho barrio, e otra casa junto a ella, todo dentro de un circuito, donde hacian las bodas de entre ellos con su cocina e aparejos de que tenían necesidad, bien grande e ampliadamente (...) e estaba el dicho almají como a manera de vergel con unos álamos u olmos altos y un pozo grande donde se lavaban los dichos moros para hacer la oración. Y en el dicho almaji había una sala grande con sus corredores en que se ponían mujeres y unos corredores grandes cerrados y largos y dentro otras casillas (...); y que se acuerda que eran los dichos edificios gran circuito detrás e llegaban hasta la ronda de la cerca e hasta la calle que atraviesa hasta la Puerta del Campo ${ }^{41}$. Desgraciadamente su derribo tuvo lugar hacia la primera quincena de septiembre de 1506, cuando de parte del dicho prior y cabildo, recogían e cobraban la madera un clérigo e lo hacía llevar en carretas e andaba pesquisando qué personas eran a cargo de la dicha madera e despojo, que según otro testigo se trataba de madera, despojo, puertas e ventanas e teja, lo que se llevaban en las carretas ${ }^{42}$.

Las referencias textuales a mezquitas en otras ciudades de la cuenca provistas de aljama mora son habituales. En el caso de Ávila, la más populosa de la región, contamos con noticias que aluden a dos mezquitas a principios del siglo XIV, una intramuros (llamada de la villa, de San Esteban o almagid mayor) y otra fuera, a los pies de la muralla (almajid de la Solana), y desde finales de esa centuria aparece la mención al almajid de la Alquibla, en la calle Empedrada, donde con el paso del tiempo se fue concentrando una vecindad importante de mudéjares. Ya a fines de la Edad Media, como consecuencia de los ordenamientos de 1480, se construyó un almagid nuevo en la morería del Berrocal, a tenor del acuerdo que permitía levantar uno nuevo en estos barrios, si se abandonaban las anteriores ${ }^{43}$.

\footnotetext{
39 ARChVa, PI. Civiles, Zarandona y Walls (O), C. 1168-1.

40 Sobre este particular, remitimos a la lectura del trabajo de MORATINOS GARCÍA, Manuel, y VILLANUEVA ZUBIZARRETA, Olatz, «Consecuencias del decreto de conversión...»

41 Ibídem, pp. 131-132.

42 Ibídem, p. 132.

43 JIMÉNEZ, Javier; ECHEVARRÍA, Ana; TAPIA, Serafín de, y VILLANUEVA, Olatz, La memoria de Alá... 2011, p. 17.
} 
Suponemos que al igual que la oración, estos mudéjares también practicaban el resto de los preceptos musulmanes, aunque apenas nos han llegado testimonios de ello, salvo que festejaban los viernes, domingos y días de fiesta específicos ${ }^{44}$. También cabe pensar que cumplían con la obligación de la limosna (zakāt) y las donaciones para obras pías (waqf o habis) que darían lugar a los bienes de moros o bienes habices, recientemente documentados para el caso abulense ${ }^{45}$.

Y si en vida el Islam mudéjar cuenta con testimonios notables, las prácticas funerarias también nos han dejado información relevante. Los cementerios mudéjares son denominados en los textos onsarios (en el caso de Ávila ${ }^{46}$ ) o almocabyr (en Valladolid ${ }^{47}$ ) y la arqueología se ha encargado de desvelarnos sus características en los casos del onsario de San Nicolás en Ávila, el almocabyr viejo de Valladolid y el cementerio de Cuéllar.

La comunidad mudéjar de Ávila contaba a fines de la Edad Media con tres cementerios: el de San Nicolás, el de Sancti Spiritus y el de cabe la Solana, según se consignan en el reparto de su piedra que se realizó inmediatamente después del decreto de 1502. En función del precio tasado para su venta, el más extenso era el de San Nicolás (tasado valorado en 37.000 maravedíes), le seguía el de cabe la Solana (12.000) y, por último, el de Sancti Spiritus (4.000) ${ }^{48}$. Las intervenciones arqueológicas llevadas a cabo entre los años 1999 y 2002 en el de San Nicolás, al sur de la ciudad, próximo al río Adaja, dejaron al descubierto más de 3.000 tumbas orientadas este-oeste o noreste-sudoeste, con los cuerpos colocados en posición decúbito lateral derecho y la mirada del difunto hacia La Meca, y depositados en simples fosas con las paredes en ocasiones reforzadas con piedras o ladrillos ${ }^{49}$. Las tumbas se señalizaban con estelas, unas dispuestas longitudinalmente sobre ellas y otras verticalmente en la cabecera y/o a los pies, de las que se han conservado varios centenares, entre las halladas in situ en este cementerio y las reaprovechadas de todos ellos como elementos constructivos (silla-

44 El mayordomo de la cofradía de Todos los Santos en Valladolid reseñó en sus libros de cuentas en más de una ocasión que los carpinteros moros que se encargaban del mantenimiento y de la construcción de las casas que administraba la cofradía no trabajaban esos días porque se trataba de una pascua de los moros. VILLANUEVA ZUBIZARRETA, Olatz, «Vivir y convivir..., 2007, p. 27.

45 ORTEGO RICO, Pablo, «Cristianos y mudéjares ante la conversión. Mercedes de moros. Mercedes de bienes de moros». Espacio, Tiempo y Forma, Serie III, Historia Medieval, Tomo 24, 2011, pp. 292-303.

46 Ibidem, p. 300.

47 El varias veces mencionado alcaller Ramiro Alcalde manda que sea enterrado en el almocabyr viejo questá aserca de la yglesia de San Pedro, y sea enterrado a par de Jence, mi muger, que Dios aya. ARChVa, PI. Civiles, Zarandona y Walls (O), C. 1168-1.

48 ORTEGO RICO, Pablo, «Cristianos y mudéjares ante la conversión...», 2011, p. 300.

49 JIMÉNEZ, Javier; ECHEVARRÍA, Ana; TAPIA, Serafín de, y VILLANUEVA, Olatz, La memoria de Alá... 2011, pp. 18-21. RUIZ ENTRECANALES, Rosa, «Excavación arqueológica en el cementerio mudéjar de Ávila», Revista de Arqueología, 231, Año XXI, 2000, p. 54. MOREDA, Javier, y SERRANO, Rosalía, «Excavación arqueológica de la necrópolis de rito islámico de San Nicolás. Ávila (mayo-junio de 2002)», Oppidum, 4, 2008, pp. 185-212. 
res, dinteles, jambas, losas, bolardos, adornos...) por toda la ciudad tras el decreto de conversión obligatoria de $1502^{50}$.

En Valladolid, unas excavaciones arqueológicas realizadas a principios de los años 90 en el subsuelo de la actual Casa del Estudiante de la Universidad de Valladolid, documentaron medio centenar de tumbas del almocabyr próximo a la iglesia de San Pedro. Las tumbas aparecían más o menos alineadas, algunas de ellas delimitadas con sencillos muretes de adobe y cubiertas con lo que en su día fueron planchas de madera o cerramientos también de adobe, pero sin rastro de las estelas que a buen seguro en su día señalizaron los enterramientos ${ }^{51}$. A falta de referencias textuales, se cree que éste fue el único cementerio del que dispuso la aljama vallisoletana hasta el siglo XV, aunque la referencia al almocabyr viejo cerca de San Pedro donde se manda enterrar Ramiro Alcalde en 1497, evidencia que todavía seguía usándose a finales de la Edad Media. Seguramente, a tenor del traslado de los mudéjares vallisoletanos a la morería en los primeros años del siglo XV, las autoridades locales decidieron también destinar un nuevo espacio para el enterramiento, acaso para que el cortejo fúnebre no tuviese que atravesar toda la villa hasta el cementerio septentrional cercano a la iglesia de San Pedro. Se eligió para el nuevo osario de los moros un emplazamiento que entonces se encontraba extramuros y al sur de la aglomeración, no muy lejos de la morería, frente al monasterio de Sancti Spiritus, donde en 1563 se levantó el convento del Carmen Calzado, luego trasformado en Hospital Militar ${ }^{52}$.

El cementerio de Cuéllar fue también parcialmente documentado arqueológicamente en 1989. Se extendía extramuros, al suroeste de la villa, en torno a la actual calle de Santa Clara, llegándose a recuperar una treintena de sepulturas semejantes a las de Ávila y Valladolid, de las que solamente cuatro correspondían a enterramientos infantiles ${ }^{53}$.

50 JIMÉNEZ GADEA, Javier, «Estelas funerarias islámicas de Ávila...», 2009. JIMÉNEZ GADEA, Javier, y VILLANUEVA ZUBIZARRETA, Olatz, «Elementos decorativos góticos en lo mudéjar abulense: las estelas funerarias", La Arquitectura tardogótica castellana entre Europa y América, Ed. Sílex, Madrid, 2011, pp. 377-388.

51 BALADO PACHÓN, Arturo; ESCRIBANO VELASCO, Consuelo; HERRÁN MARTíNEZ, José Ignacio, y SANTAMARÍA GONZÁLEZ, José Enrique, «La Maqbara de Valladolid. Un interesante cementerio mudéjar». Revista de Arqueología, n.ำ127, noviembre, 1991, pp. 38-45. MARCOS VILLÁN, Miguel Ángel PALOMINO LÁZARO, Ángel Luis, y HOYAS DÍEZ, José Luis, «Excavaciones arqueológicas en la Casa de la Beneficencia de Valladolid (calle Chancillería, n. 12, 13 y 14)». Arqueología Urbana en Valladolid. Junta de Castilla y León, Consejería de Cultura y Bienestar Social. Valladolid, 1991, pp. 215-229. VILLANUEVA ZUBIZARRETA, Olatz, «Los escenarios de la sociabilidad...», 2010, p. 366-368.

52 MORATINOS GARCÍA, Manuel, y VILLANUEVA ZUBIZARRETA, Olatz, «Consecuencias del decreto de conversión al cristianismo de 1502 en la aljama mora de Valladolid», en Sharq al-Andalus, Revista de Estudios Mudéjares y Moriscos, vol. 16-17 (1999-2002), Homenaje Leonard P. Harvey, 2004. pp. 121-144.

53 RUIZ DE MARCO, A.; ARELLANO, O. I.; HERAS, E.; LERÍN, M.; BARRIO, R.; TARANCÓN, M. J.; BALADO, A.; ESCRIBANO, C.; HERRÁN, J. I.; SANTAMARÍA, J. E., y VEGA, D., «Las necrópolis de rito islámico en Castilla y León», Nvmantia, Arqueología en Castilla y León, 4, 1993, pp. 207-208. Sobre los resultados del estudio antropológico realizado sobre los restos óseos recuperados: HERRERÍN LÓPEZ, Jesús, La Maqbara de Santa Clara. Estudio de una necrópolis musulmana en Cuéllar, Obra Social y Cultural de Caja Segovia 27, Segovia, 2004. 


\section{LA LEY E AÇUNNA DE MOROS, USADA E GUARDADA ENTRE LOS MOROS E ALJAMA DE BURGOS}

La comunidad de Burgos no se encontraba entre las más populosas de la cuenca del Duero, ya que si tenemos en cuenta las cantidades que tributaba a finales de la Edad Media, estaba compuesta por un par de cientos de mudéjares. Pese a ello, a continuación lo veremos, no parece que decayese en la observancia de los preceptos musulmanes, y seguramente bien podría aplicarse a toda la aljama lo que decía en 1489 una convecina cristiana, refiriéndose a uno de sus habitantes: "que para ser moro, que segund moro e en su ley que era buen moro e de buena conçiençia e fama» ${ }^{54}$. Orgullosa, en ese mismo año, la aljama burgalesa, en un escrito de defensa de una judía que quería convertirse al islamismo decía: "que en nuestro Consejo, ay letrados e personas tanto çientíficas e muy çelosos e deseosos de la justicia» ${ }^{55}$.

La comunidad mudéjar burgalesa adolece todavía de un estudio en profundidad, pese a los trabajos ya publicados ${ }^{56}$.

En cuanto a sus orígenes, por ahora poco podemos decir, salvo remitir a la visión general de los musulmanes de la Cuenca del Duero trazada al principio de este trabajo. Según López Mata ${ }^{57}$ los moros burgaleses se avecindaron en dos barrios próximos, que este autor llama morerías superior e inferior, separadas por la Calle Tenebregosa, tramo final de la actual de Fernán González. Siguiendo también a este cronista, parece que la más antigua fue la morería inferior, entre la cerca y las iglesias de Santa María de Viejarrúa y Santa Águeda. Esta zona de la ciudad, que en 1404 se designa simplemente como morería ${ }^{58} \mathrm{o}$, a causa de acoger el almagí, barrio de la mezquita ${ }^{59}$, acabó por resultar insuficiente para esta población y se extendió hacia la parte alta durante el reinado de Enrique IV ${ }^{60}$.

54 Declaración de la testigo Catalina, criada de Ferrand García de Estella, refiriéndose a maestre Braén, yesero. ARChVa, PI. Civiles. Alonso Rodríguez (D), C. 0002.002, fol. 91r.

55 CARRETE PARRONDO, Carlos, «Judería soriana y morería burgalesa: una historia de amor», Estudios Mirandeses /VIII (1988), p. 60.

56 Hemos de señalar algunas pocas obras, entre ellas: HUIDOBRO SERNA, Luciano, «Los moros de Burgos y su influencia en el arte», Boletín de la Institución Fernán González, n.ำ 105, 1948, pp. $222-225$. LÓPEZ MATA, Teófilo, «Morería y Judería», Boletín de la Real Academia de la Historia, n.․ 129, 1951, pp. 335-384. TORRES BALBÁS, Leopoldo, Algunos aspectos del mudejarismo urbano medieval, Real Academia de la Historia, Madrid, 1954 y «Actividades de los moros burgaleses en las artes y oficios de la construcción», Al-Andalus: Revista de las Escuelas de Estudios Árabes de Madrid y Granada, vol. 19, n. (1954), pp. 197-202. Y más recientemente, CADIÑANOS BARDECI, Inocencio, Judíos y Mudéjares en la provincia de Burgos, Excma. Diputación Provincial de Burgos, Vitoria, 2011.

57 LÓPEZ MATA, Teófilo, «Morería y Judería», 1951, pp. 335-384

58 CASADO ALONSO, Hilario, La propiedad eclesiástica en la ciudad de Burgos en el siglos XV: El Cabildo Catedralicio, Universidad de Valladolid, Valladolid, 1980, pp. 171-173.

59 Así se la llama en documentos del Archivo Catedralicio recogidos por López Mata: «in orto tras la mezquita» (año 1260), o "en el barrio que se solía llamar de la mesquita e se nombra agora el barrio de las Canales» (año 1465). LÓPEZ MATA, Teófilo, «Morería y Judería», 1951, p. 339.

60 TORRES BALBÁS, Leopoldo, Algunos aspectos del mudejarismo urbano..., 1954, p. 26. 
Al otro lado de la calle Tenebregosa los musulmanes mostraron preferencia por los solares aledaños al cerro del castillo, especialmente la Calle de las Armas, que señalaba el límite de la población por lo alto ${ }^{61}$, pero cuyo trazado exacto nos es desconocido ya que se quemó en 1475 durante el cerco a la fortaleza ${ }^{62}$. Por encima de la morería superior se encontraba el barrio Quemadillo, que acogió también a bastantes mudéjares. Sin embargo, a pesar de extenderse hacia la parte alta de la ciudad, no se abandonó el espacio cercano a la puerta de Santa Águeda, que siguió habitado por mudéjares hasta el momento de la conversión.

Contaron también con un cementerio propio extramuros, ubicado en la glera al otro lado del río ${ }^{63}$, en un espacio, al igual que el de la morería alta, hoy muy transformado.

Esta a aljama carecía de oficiales propios que juzgasen los asuntos de la comunidad, ya que estaba sometida a los alcaldes ordinarios de la ciudad en virtud de un privilegio que concedió Fernando IV al Concejo en $1304^{64}$, ratificando disposiciones anteriores de su padre Sancho IV. Esta situación se mantuvo durante el resto de la etapa mudéjar, como se desprende de un pleito entre moros iniciado en 1489 , en el que la demanda en primera instancia fue presentada ante un alcalde cristiano ${ }^{65}$.

Junto a la aljama residente en el núcleo urbano, a las afueras de la ciudad, el Hospital del Rey, anejo al poderoso Monasterio de las Huelgas Reales, acogía a un pequeño grupo a su servicio ${ }^{66}$, no constituido en aljama, acaso como un recuerdo de los moros cautivos que poseyeron algunos monasterios en la Alta y Plena Edad Media ${ }^{67}$ y que más tarde fue de moriscos hasta el momento de su expulsión ${ }^{68}$.

A pesar de los indicios de que los moros burgaleses conservaban en gran medida sus rasgos religiosos y culturales, no estuvieron exentos de especiales

61 En el apeo de propiedades del cabildo catedralicio de 1404, que recoge $\mathrm{H}$. Casado, las casas que poseía la iglesia mayor en esta calle lindaban con la cuesta del castillo. CASADO ALONSO, Hilario, La propiedad eclesiástica..., 1980, p. 169.

62 LÓPEZ MATA, Teófilo, «Morería y Judería», 1951, pp. 335-342.

63 Ibidem, p. 355.

64 «... e mando que los pleitos que son e los que acaescieren entre los moros que moran en la villa de Burgos e en su alfoz, que los libren los alcaldes de la dicha ciudad...», CARRASCO MANCHADO, Isabel, De la convivencia a la exclusión, 2012, p. 142.

65 ARChVa, PI. Civiles. Alonso Rodríguez (D), C. 0002.002.

66 Fernando IV exime de tributos en 1304 a doce moros horros del real monasterio, HUIDOBRO SERNA, Luciano, «Los moros de Burgos y su influencia..., 1948, p. 224. En 1332 se cuentan catorce musulmanes que sirven en dicho hospital, CERRO HERRANZ, María Filomena, «Notas para la economía de un centro hospitalario. El Hospital del Rey en Burgos", Norba. Revista de Arte, Geografía e Historia, 4, 1983, pp. 285-288.

${ }_{67}$ PÉREZ CELADA, Julio Antonio, «Notas sobre los musulmanes en algunos núcleos del Camino de Santiago en Castilla», Actas VII Simposio Internacional de Mudejarismo, Instituto de Estudios Turolenses, Teruel, 1999, pp. 185-193.

${ }^{68}$ En el Censo de la Inquisición de 1594 se consignan dos familias que suman diez individuos. CADIÑANOS BARDECI, Inocencio, Judíos y Mudéjares..., 2011, p. 311. 
trabas, como la prohibición, ya mencionada, de poseer oficiales propios que librasen las causas internas de la comunidad, que debía recurrir a los alcaldes ordinarios de la ciudad, o la obligación de satisfacer a la parroquia el diezmo correspondiente a las huertas labradas por ellos ${ }^{69}$. Desconocemos si contaban con otros oficiales más allá del alfaquí, cargo que ya aparece en esta morería a mediados del siglo XIII ocupado por un tal don Yuçef ${ }^{70}$, más tarde, en una fecha indeterminada del siglo XV, por Ibraim ben Ali ben Farax Ruy Díaz ${ }^{71}$ y de nuevo en 1489 por «Braemi alfaquí de los moros», que testifica en un pleito ${ }^{72}$.

En este mismo proceso judicial, que ahora nos interesa por estar sujeto a la ley y açuna de moros, aparecen como testigos un buen número de moros burgaleses, señaladamente muchos dedicados a los oficios de la construcción, al tiempo que se descubren algunos detalles sobre la comunidad. La causa del pleito está en la venta de parte de los bienes de un huérfano a su propio tutor. El huérfano, Alí de Menimbre ${ }^{73}$, que hacía tiempo que había alcanzado la mayoría de edad, reclamaba a las herederas de su tutor y comprador de una casa heredada de su padre, su tío maestre Braén yesero, que le restituyeran su propiedad por considerar que la venta iba en su perjuicio ${ }^{74}$ y que existían irregularidades en el modo de concluir la tutela.

Durante el proceso cada una de las partes alegaba que estaba en vigor una legislación distinta. Por una parte, Alí de Menimbre invocaba la legislación castellana «segund ley de christianos e segund verdadera justiçia donde bibimos» ${ }^{75}$,

69 Sucesivas sentencias judiciales, desde 1369 hasta 1496, requieren este impuesto a los mudéjares que cultivaban huertas incluidas en la demarcación de la parroquia de San Lesmes, propiedad del Monasterio de San Juan. PEÑA PÉREZ, Francisco Javier, "Los moros pagan el diezmo eclesiástico», Estudios de Historia y Arte. Homenaje al profesor D. Alberto Ibáñez Pérez, Universidad de Burgos, Burgos, 2005, pp. 117-120.

70 Se le nombra en el testamento del obispo don Juan Domínguez, muerto en 1246. HUIDOBRO SERNA, Luciano, «Datos para la topografía del Burgos medieval.», Boletín de la Institución Fernán González, 105, 1948, p. 223.

71 Este alfaquí burgalés ratifica el dictamen solicitado por el de Valladolid al alfaquí de la aljama de Ávila acerca de si es lícita la azala sobre pieles sin curtir. FERNÁNDEZ Y GONZÁLEZ, Francisco, Estado social y político de los mudéjares de Castilla, Edición de M. García Arenal, Hiperión, Madrid, 1985, p. 395.

72 ARChVa, PI. Civiles. Alonso Rodríguez (D), C. 0002.002, fol. 78r.

73 A lo largo del proceso se emplean indistintamente diversas variantes del apellido: Menimbre, Membibre, Membimbre, Bembibre o Minimbre, acaso referido a las localidades de Bembibre (León) o Belbimbre (Burgos). Esta última localidad se encuentra en el Campo de Muñó, del cual proceden varios de los topónimos que identifican a los moros burgaleses, como Yuça de Villavieja (Villavieja de Muñó), Audalla de Pampliega, Abdalla de Cañizar (seguramente Cañizar de Argaño) o Hamete de Muñó (hoy despoblado perteneciente al término de Villavieja de Muñó). Apoyan también una especial vinculación de los mudéjares de la aljama de Burgos con esta comarca algunos documentos del Archivo Catedralicio que recogen a varios de estos testigos del pleito como arrendadores de préstamos en poblaciones de esta zona, que, por otra parte, se encontraba sujeta al señorío concejil de la ciudad de Burgos.

74 Las Partidas reconocen al huérfano la restitutio in integrum, el derecho a anular cualquier negocio ocurrido durante su menor edad que se considerase perjudicial para sus intereses. Según las Partidas, (Partidas, VI, 19) este derecho debía solicitarse al juez hasta cuatro años después de alcanzar los veinticinco, edad a la que ya podía disponer plenamente de su hacienda.

75 ARChVa, PI. Civiles. Alonso Rodríguez (D), C. 0002.002, fol. 89r. 
mientras que las herederas de su tío maestre Braén yesero, argüían que en este caso regía la «ley e açunna de moros» ${ }^{76}$.

Evidentemente, cada litigante defendía uno u otro derecho en función de sus intereses particulares, sin reparar en cuál era más acorde con la identidad cultural de la aljama, y presentaba a sus testigos, en su inmensa mayoría moros, para probar una postura o la contraria. Esta ausencia de reflexión de la comunidad sobre los rasgos que los historiadores entendemos como distintivos, es notoria también en los procesos que enfrentaron a varios hortelanos mudéjares con el Monasterio de San Juan, a causa del pago de diezmos desde finales del siglo XIV hasta las vísperas de la conversión. Como señala F. J. Peña, los litigantes apenas esgrimían argumentos, pues ni siquiera exponían su condición de no cristianos para excusar este impuesto eclesiástico ${ }^{77}$.

Como ya hemos señalado, entre las causas de la demanda se encontraba la venta de una casa en el barrio Quemadillo ${ }^{78}$ por parte de Alí de Menimbre a su tío y tutor maestre Braén yesero durante su menor edad. Años después, Alí pretendió recuperar dicha propiedad alegando que la transacción fue irregular y que al cesar la curatela de su tío, no se presentó cuenta de los bienes que le fueron encomendados, por lo que reclamaba a sus herederos la anulación del negocio. El derecho romano, y en concreto las Partidas, reconocía al huérfano la restitución por entero, es decir, el derecho de anular cualquier transacción que considerase contraria a sus intereses, aún cuando fuera causada por él mismo, en los cuatro años siguientes a cumplir los veinticinco y por tanto la mayoría de edad ${ }^{79}$.

La parte contraria, representada por maestre Braén de los Escudos, carpinte$\mathrm{r}^{80}$, casado con doña Fátima, viuda de maestre Braén yesero, no dudaba en rechazar la reclamación esgrimiendo la «ley e açunna de moros, usada e guardada entre los moros e aljama de la dicha çibdad» ${ }^{81}$, según la cual al alcanzar el huérfano los dieciocho años pasaría a tomar posesión de su herencia y a recibir cuen-

76 Ibídem, fol. 21r.

77 PEÑA PÉREZ, Francisco Javier, «Los moros pagan el diezmo eclesiástico»..., 2005, pp. 117-120.

78 Como ya dijimos, este barrio se encontraba en la parte alta de la ciudad y lindante con la morería.

79 «Otrosi dezimos, que faziendo el menor de veinte e cinco años pleyto alguno, o postura, que fuesse a su daño o cambiando su debdo por otro peor, o faziendo otra mudación nuevamente, en qual manera quier, por que se empeore su fazienda, o se menoscabassen sus bienes, o su derecho; que puede pedir al juez, que faga desfazer el pleyto, o la mudación que fizo a su daño, e qual faga mejorar, e entregar, lo que oviesse menoscabado por cualquier destas razones sobredichas» (Partidas, VI, 19,5). Sobre la restitutio in integrum o restitución por entero: MERCHÁN ÁLVAREZ, Antonio, La tutela de los menores en Castilla hasta fines del siglo XV, Publicaciones de la Universidad de Sevilla, Sevilla, 1976. pp. 61-71.

80 Este carpintero aparece varias veces en la documentación del Archivo Catedralicio hasta las vísperas de la conversión. Se hace cargo de varios préstamos en 1486 en Villamorón (ACBu, RR-27 Unidad Documental. f. 165v), en 1500 en Tapia (ACBu, RR-33 Unidad Documental, fols. 68-70), en 1501, manifestando que Juan de Arcaya carpintero ha gastado 30.000 mrs. en casas que ha edificado (Archivo de la Catedral de Burgos, RR-34 Unidad Documental, f. 137r) y de nuevo en ese año junto a su hijo Braén de los Escudos el mozo, como arrendatarios de otro préstamo en Sandoval de la Reina (ACBu, RR-33 Unidad Documental, f. 13v).

81 Declaración del testigo Yuça de Perros, ARChVa, Pl. Civiles, Alonso Rodríguez (D). C. 002.002, fol. 21r. 
ta de su curador sin que mediara juez alguno. Esta idea se ve reforzada por las Leyes de Moros del siglo XIV, que afirman que a la hora de dar cuenta de los bienes custodiados, el testimonio del tutor es suficiente para dar por buena su gestión ${ }^{82}$, lo que anularía la posibilidad de restitución por entero que sí reconoce el derecho castellano.

La opinión de los testigos interrogados al respecto no fue unánime y su declaración apoyaba o desmentía el uso de esta costumbre en la aljama, dependiendo de la parte que los había presentado, pero las sucesivas instancias por las que pasó el proceso, desde el alcalde ordinario de la ciudad de Burgos ${ }^{83}$ hasta la Real Chancillería en su sentencia en grado de revista ${ }^{84}$, rechazaron la demanda de Alí de Menimbre, reconociendo implícitamente que los moros burgaleses se regían por normas distintas al derecho común castellano.

El reconocimiento de la identidad musulmana de estos mudéjares por parte de las autoridades cristianas se manifiesta también en otros detalles del proceso, entre ellos la fórmula de juramento diferenciada para los testigos de ambos credos, como se recoge también en otros muchos documentos contemporáneos. Encontramos dos fórmulas algo distintas:

- «juraron por el nombre de Alá todopoderoso façedor del çielo e de la tierra el que ellos dizen que puso las virtudes en la boca de Mafoma e por las palabras del Alcorán do quier que estavan escritas e como buenos moros temiendo Alá e guardando sus conçiençias dirán la verdad de todo aquello que supiesen e les fuese preguntado açerca e sobre razón desto que heran presentados por testigos e que non lo dexaran de dezir por dádiba ni promesa que les fuese dada ni prometida ni por afiçión ni deudo que touiesen más con la una parte que con la otra, ni por otra razón alguna e que sy así lo fiziesen que Dios Nuestro Señor que es Padre todopoderoso les ayudase en este mundo e les apiadase e sy el contrario de la verdad dixesen que en la gelo demandase mal e caramente commo aquelos moros que a saviendas juran en nombre de Alá en bano, e que sus animas fuesen al ynfierno donde ban los dañados que nunca han redençión e fueles echada la confesyón del dicho juramento e dixeron: Sy, juro, e Amén» ${ }^{85}$.

- «juró [a] Alá, poderoso Hazedor del çielo e de la tierra e del mar e de las arenas e a las palabras del Alcorán que como buen moro diría la verdad de lo

\footnotetext{
82 «Otrosy, el tutor es creydo de lo que dixiere que espendió sobre el huerfano, et asymesmo el tutor es esgastado [es] creydo [de] lo que espendiere sobre él. Et quando el huerfano llegare á edat, et dixiere el su tutor quel tornó su aver, non es creydo, nin reciban su dicho synon con testimonios que lo testimuñen; et non enpeçe que merquen con el algo del huerfano, et non es tenudo el tutor á pagar de su algo nada, et non enpeçe que buelvan el gobierno del tutor con el gobierno del huerfano, sy mejoria oviere el huerfano en ello; et conviene que el tutor del huerfano que ensanche sobre él en el gobierno et en el vestirse, segunt su facienda; et non enpeçe quel castigue», Memorial Histórico Español: Colección de documentos, opúsculos y antigüedades, que publica la Real Academia de la Historia. Tomo V, Tratados de legislación musulmana. $1 .^{\circ}$ Leyes de Moros del siglo XIV, Real Academia de la Historia, Madrid, 1853, p.166.

${ }^{83}$ Sentencia pronunciada el 5 de octubre de 1489, ARChVa, Pl. Civiles. Alonso Rodríguez (D), C. 0002.002 , fol. 133v.

${ }^{84}$ Dada el 10 de enero de 1494, Ibídem, fol. 42r.

85 ARChVa, PI. Civiles. Alonso Rodríguez (D), C. 0002.002 , fols. 53 y 160.
} 
que supiese e preguntado le fuese sobre razón desto que era preguntado por testigo e que non lo dexara de dezir por indiçia de ganar ni por temor de perder ni por dádiba ni promesa que le fuese dada o prometida ni por otra razón alguna e que sy asi lo hiziese que Alá le apiadase e sy el contrario de la verdad dixese que Alá le enviase a quellas partes donde ban los dañados que non han redençión e fuele echada la confesión del dicho juramento e dixo: Sí, juro» ${ }^{86}$.

El Espéculo de Alfonso X prevé una fórmula más larga ${ }^{87}$ que se debía recitar en la puerta de una mezquita, de lo que no se hace mención en el proceso burgalés.

La propia divergencia de los testigos y las tachas puestas a algunos de ellos hacen patentes enemistades y tensiones en el interior de la comunidad mudéjar, en la que, al menos en lo tocante a este caso, se descubren dos grupos, cada cual respaldando a una de las partes litigantes. Así, por un lado aparecen los partidarios de maestre Braén de los Escudos, muy cercano al alfaquí y a otras figuras de la comunidad, que defendían a «las moras», como a menudo se refieren genéricamente a las herederas de maestre Braén yesero. $Y$, enfrentados, aquéllos que respaldaban al demandante Alí de Menimbre, hombre de mucha menor influencia, que aborrecían profundamente a los contrarios, quienes parecen ser las «fuerzas vivas» de la aljama. Este resentimiento es patente en las alegaciones del procurador de Menimbre, quien no dudaba en motejar al alfaquí de «perjuro e ha fecho tres o quatro juramentos falsos» 88 .

No solo los mudéjares de Burgos recurrían a la justicia real (amén de estar obligados a ello), sino que vemos la misma respuesta en otras comunidades del Duero $^{89}$, donde igualmente constituían grupos reducidos y las rencillas en su seno debían de estar a la orden del día.

Abundan en este proceso los testigos dedicados a los oficios de la construcción, tanto por ocupar a una buena porción de los moros burgaleses ${ }^{90}$, como por

\footnotetext{
${ }^{86}$ ARChVa, PI. Civiles. Alonso Rodríguez (D), C. 0002.002 , fol. 106r.

87 «Jura me tú, Fulan moro, que por aquel Dios que non a otro si non Él, aquel que es demandor e conosçedor e destruidor e alcançador de todas las cosas, que crió aquesta parte de alquibla contra que tú fazes oración. E otrossí juras me por lo que reçebió Jacob de la fe de Dios para sý e para sus fijos e por el omanage quél fizo del guardar, et por la verdat que tú tienes que puso Dios en la boca de Mahomad, hijo de Abdalla, quando I[e] fizo su proffecha e su ma[n]dadero, segunt que tú crees, que esto que yo digo que non es verdat, o que es assí como tú dizes. Et que si mentira jurares, que seas apartado de todos los bienes de Dios e de Mahomad, aquel que tú dizes que fue su proffecta e su mandadero, e non ayas parte con él nin con los otros proffectas en njnguno de los paraísos, mas todas las penas que dize el Alcorán que dará Dios a los que non creen en la tu ley, vengan sobre tý», CARRASCO MANCHADO, Ana Isabel, De la convivencia a la exclusión..., 2012, p. 101.

${ }^{88}$ ARChVa, PI. Civiles. Alonso Rodríguez (D), C. 0002.002, fol. 115v.

89 J. L. Pascual recoge este comportamiento en procesos entre moros de Ávila y Segovia, PASCUAL CABRERO, José Luis, «Pleito por la herencia de Abdallá de Santo Tomé..., 2013, pp. 284, y también se constata en Aranda de Duero, CANTERA MONTENEGRO, Enrique, "Las comunidades mudéjares de las diócesis de Osma y Sigüenza a fines de la Edad Media", Revista de la Facultad de Geografía e Historia, n.. 4, 1989, p. 160 .

${ }^{90}$ Las dos ocupaciones principales de los mudéjares burgaleses eran la construcción y el trabajo de la huerta, LÓPEZ MATA, Teófilo, «Morería y Judería», 1951, pp. 344-356.
} 
tratarse de la profesión de los litigantes, pues tanto Alí de Menimbre como Braén de los Escudos, eran carpinteros y se reconocía al difunto Braén, tutor de Alí, por su oficio de yesero. Es evidente que la reducida población de la aljama no requería un grupo tan grande de maestros albañiles y que la mayor parte de sus clientes no seguían la ley de Mahoma. Pero tampoco debía ser bastante la mano de obra mudéjar para satisfacer la demanda y debieron buscar obreros cristianos, costumbre limitada por las Ordenanzas de Haro de $1466^{91}$, y que penaba duramente el Concejo de Burgos en 1485 «por quanto entre los dichos moros desta cibdad ay algunos dellos que son oficiales e maestros de labrar de yeso e para labrar del dicho oficio alquilan mujeres cristianas que les sirven de amasadoras... mandan que los dichos elseros no alquilen las dichas mujeres cristianas... so pena de sesenta azotes... o que labren personas cristianas, pero sin comunicar con los moros ${ }^{92}$. Esta práctica, como vemos penada con severidad por las autoridades municipales, debía de tratarse de un uso común, pues la testigo Catalina elesera, criada que fue de Ferrand García de Estella, reconoce sin rubor «que esta testigo trabtava e le labrara de contino con él [maestre Braén yesero] de yelso» ${ }^{93}$, quizás porque el castigo sólo estaba previsto para el moro, quien hacía varios años que había fallecido, seguramente antes de promulgarse la ordenanza.

\section{CONCLUSIÓN}

La inexistencia de un poblamiento andalusí en la Cuenca del Duero y la exigüidad de la población mudéjar asentada en aljamas repartidas por los principales núcleos urbanos de la cuenca, han hecho suponer a los historiadores que los moros castellanos apenas habían conservado los rasgos que los distinguían como musulmanes. El hallazgo de ciertos documentos escritos y patrimoniales desvelan hoy que estas comunidades mantuvieron con fuerza algunos elementos de identidad puramente islámicos hasta las mismas fechas de su bautismo en 1502.

Esta circunstancia no resulta llamativa en las populosas morerías de Ávila, Valladolid o Arévalo, donde entre varios cientos de habitantes no extraña que se conservaran bastantes usos de la tradición musulmana. Sin embargo, en otras menores, con una población más exigua, y alejadas de los principales centros del mudejarismo peninsular, como sería el caso de Burgos, se percibe una situación no muy diferente. En los últimos años del siglo XV, en vísperas de la conversión, el grado de islamización de estos moros burgaleses era elevado, conservando sus

91 «que ningun obrero nin obrera non fuese osado de se alquilar para los dichos [judíos] e moros fasta ser acabada la misa de la alba. E sy fasta aquel tiempo non fallaren christiano que los alquile, que los tales obreros e obreras pidan liçençya al alcalde que agora es o fuere de aquí adelante», CANTERA MONTENEGRO, Enrique, «La comunidad mudéjar de Haro (La Rioja) en el siglo XV», En la España Medieval, n.ำ 4, 1984, p. 166 .

92 LÓPEZ MATA, Teófilo, «Morería y Judería», 1951 , p. 354.

93 ARChVa, PI. Civiles. Alonso Rodríguez (D), C. 0002.002, fol. 90v. 
nombres arábigos, sus modos de organización interna según la ley coránica y su alfaquí que velaba porque no decayese la práctica religiosa islámica. De hecho, esta situación fue expresamente reconocida por las autoridades castellanas, quienes si bien privaron a la aljama burgalesa de una administración de justicia propia, los alcaldes de la ciudad, y también los oidores de la Real Chancillería, la distribuyeron de acuerdo al ordenamiento jurídico islámico.

En general, llama la atención al historiador que los mismos poderes que por una parte promovían la conversión al cristianismo de sus minorías, fueran los que legislaran medidas represivas, por otra, marcando la diferenciación religiosa por medio de la ley, los distintivos en el vestido y el apartamiento en barrios específicos de esas comunidades. Fueron, según hemos visto, los mismos musulmanes quienes más cuidaron de la observancia de sus preceptos, pero si atendemos a algunos testimonios, debió de ser más por costumbre y tradición heredada, que por una convicción profunda y una verdadera conciencia de su significado. Tanto es así, que este hecho quizás debería hacer plantearnos hasta qué punto coinciden los rasgos que los historiadores entendemos como propios y distintivos de esta minoría, con lo que ellos verdaderamente pensaban que era ser buen moro. 
